\title{
Massive Ascites as the Initial Manifestation of Mantle Cell Lymphoma: A Challenge for the Gastroenterologist
}

\author{
Ipek Yonal $^{\mathrm{a}} \quad$ Aslı Ciftcibasi $^{\mathrm{b}}$ Suut Gokturk ${ }^{\mathrm{b}}$ \\ Mustafa Nuri Yenerel $^{a} \quad$ Filiz Akyuz $^{\mathrm{b}}$ Cetin Karaca $^{\mathrm{b}}$ \\ Kadir Demir ${ }^{b}$ Fatih Besisik $^{b} \quad$ Sevgi Kalayoglu-Besisik ${ }^{a}$ \\ Division of ${ }^{\mathrm{a}} \mathrm{Hematology}$ and ${ }^{\mathrm{b}} \mathrm{G}$ astroenterohepatology, Department of Internal \\ Medicine, Istanbul University Medical Faculty, Istanbul, Turkey
}

\section{Key Words}

Cytomorphology - Effusions involving peritoneal and pericardial cavities - Flow cytometric immunophenotyping - Lymphoproliferative diseases - Mantle cell lymphoma

\begin{abstract}
Involvement of the serosa may be the presenting feature in a wide and complex variety of lymphoproliferative diseases, with differing clinical outcomes covering a spectrum of benign and malignant conditions. Effusions involving peritoneal and pericardial cavities are uncommon during the course of hematological malignancies. Obstructive and/or infiltrative tumor mass or vascular leakage due to stimulation by vascular endothelial growth factor contribute to the pathogenesis. In addition to clinical findings, cytomorphology and flow cytometric immunophenotyping of the serosal fluid yield valuable information in the differential diagnosis of lymphocytic infiltrates. Herein, we describe the case of primary mantle cell lymphoma in a 75-year-old man presenting with abdominal fullness and weight loss, suggesting a gastrointestinal pathology.
\end{abstract}

\section{Introduction}

A diverse and complex variety of lymphoproliferative diseases may involve the serosa with different clinical outcomes covering a spectrum of benign and malignant conditions $[1,2]$. Lymphoid or plasma cell infiltrates are commonly observed in pleural or peritoneal biopsy samples in response to a variety of stimuli, which are delineated as reactive inflammatory lesions of the surfaces. The accompanying lymphocytic 
inflammatory reactions in tuberculosis, fungal infections and connective tissue disease are especially striking. Also, a variety of neoplasms including lymphohistiocytoid mesothelioma, serosal thymic epithelial tumor and inflammatory myofibroblastic tumor may present with rich lymphoid, plasmacellular or histiocytic infiltrates causing the unaware pathologist to consider any such lesion as a hematologic neoplasm. In the course of hematologic malignancies, the invasion of various serosal sites is usually accounted for secondary involvement in subjects with known lymph node, marrow-based or extranodal disease. Primary pericardial, pleural and peritoneal involvement is rare. Clinical findings are important in the differential diagnosis of lymphocytic infiltrates. Cytomorphology and immunohistochemistry have a high diagnostic yield. Flow cytometry (FCM) and polymerase chain reaction are ancillary studies [1,3]. Peritoneal involvement occurs in many subtypes of lymphomas, diffuse large B-cell lymphoma being the most frequent. Peritoneal lymphomatosis can mimic peritoneal carcinomatosis and must be ruled out in patients with ascites, hepatosplenic lesions and unidentified cause of peritoneal thickening on computed tomography (CT) [4]. In this report, we describe the case of a primary mantle cell lymphoma (MCL) in a 75-year-old man who presented with abdominal fullness and weight loss, bringing to mind a gastrointestinal pathology.

\section{Case Report}

A 75-year-old male was admitted to the gastroenterohepatology department with a 3-month history of abdominal fullness and weight loss. His medical history was significant only for an appendectomy. There was no history of illicit drug use or chronic alcohol consumption. Physical examination revealed pallor, cachexia, bilateral lower limb edema and decreased breath sounds at the middle zone of the right and the base of the left lung. His abdomen was protuberant with bulging flanks and a positive fluid thrill. The edge of the spleen descended to the level of the pelvis, palpable $7 \mathrm{~cm}$ below the left costal margin, and the liver was palpated $2 \mathrm{~cm}$ below the right costal margin. On blood count, there was mild anemia with a hemoglobin concentration of $10 \mathrm{~g} / \mathrm{dl}$, a white blood cell count (WBC) of $10,300 / \mathrm{mm}^{3}$ and a platelet count of $85,000 / \mathrm{mm}^{3}$. Biochemical tests showed elevated lactate dehydrogenase (LDH) and decreased albumin $(2.4 \mathrm{~g} / \mathrm{dl})$; alkaline phosphatase, gamma-glutamyltransferase, serum aspartate aminotransferase and serum glutamic pyruvic transaminase were normal. Blood smear revealed 74\% lymphocytes, $21 \%$ neutrophils and $5 \%$ monocytes. The lymphocytes were small with irregular nuclei (fig. 1). On FCM of the peripheral blood, there were pan-B cell antigens (CD19, CD20), CD5, FMC7 and a weak CD23 expression, compatible with a diagnosis of chronic lymphocytic leukemia/small lymphocytic lymphoma and MCL. On CT scan of the neck and thorax, multiple minimally enlarged cervical and axillary lymph nodes and bilateral pleural effusions more evident in the right lung were detected. Abdominal CT scan showed massive ascites, spleen and liver sizes measuring 23 and $18 \mathrm{~cm}$, respectively. Radiologically, there was no sign suggesting cirrhosis of the liver. Also, there was increased density in the form of streak infiltrations in the mesenteric area without concomitant enlargement of the abdominal lymph nodes. A diagnostic and therapeutic paracentesis was performed. Analysis of the bloody ascitic fluid showed an exudate with a WBC of $39,400 / \mathrm{ml}$ and a red blood cell count (RBC) of $169,000 / \mathrm{ml}$ and the following results on biochemical analysis: ascitic total protein $3.6 \mathrm{~g} / \mathrm{dl}$ (serum $5.7 \mathrm{~g} / \mathrm{dl}$ ), glucose $38 \mathrm{mg} / \mathrm{dl}$ (serum $68 \mathrm{mg} / \mathrm{dl}$ ), LDH $506 \mathrm{U} / \mathrm{l}$ (serum $733 \mathrm{U} / \mathrm{l}$ ), triglyceride $48 \mathrm{mg} / \mathrm{dl}$ (serum $196 \mathrm{mg} / \mathrm{dl}$ ) and albumin $2.6 \mathrm{~g} / \mathrm{dl}$ (serum $3.3 \mathrm{~g} / \mathrm{dl}$ ). Cytocentrifuge preparation of the patient's ascitic fluid demonstrated small to medium-sized lymphocytes with sparse cytoplasm and irregular nuclei containing moderately dispersed chromatin (fig. 2). FCM analysis of the ascitic fluid showed the expression of pan-B cell antigens (CD19, CD20), CD5, FMC7 and a weak expression of CD23 similar to the findings in peripheral blood ( $\underline{\text { fig. } 3}$ ). Pleural fluid was removed for symptomatic relief. Analysis of the bloody pleural fluid revealed an exudate with a WBC of $12,300 / \mathrm{ml}$ and a RBC of $155,000 / \mathrm{ml}$ and the following results on biochemical analysis: pleural total protein $3.7 \mathrm{~g} / \mathrm{dl}$ (serum $5.4 \mathrm{~g} / \mathrm{dl}$ ), glucose $71 \mathrm{mg} / \mathrm{dl}$ (serum $98 \mathrm{mg} / \mathrm{dl}$ ), LDH $307 \mathrm{U} / \mathrm{l}$ (serum $434 \mathrm{U} / \mathrm{l}$ ) and albumin $2.3 \mathrm{~g} / \mathrm{dl}$ (serum $3.2 \mathrm{~g} / \mathrm{dl}$ ). Cytocentrifuge preparation of the patient's pleural fluid showed the same morphology as described 
for the ascitic fluid (fig. 4). Gram and acid-fast stains of the ascitic and pleural fluids were negative. Ascitic and pleural fluid cultures remained negative on conventional and BACTEC culture methods. Cytological studies demonstrated the presence of atypical small lymphoid cells both in ascitic and pleural fluid samples. Bone marrow biopsy revealed a nodular and interstitial infiltration by small lymphocytes staining positive for pan-B cell antigens, cyclin D1 and CD5 and negative for CD10 and CD23. Cytogenetic analysis of the bone marrow showed a normal karyotype.

The patient was diagnosed as stage IV MCL with high IPI score [5]. He was commenced on cyclophosphamide, adriablastina, vincristine and prednisolone (CHOP) chemotherapy. By the time of the second cycle of chemotherapy, pleural and ascitic fluid accumulation moderately decreased requiring less frequent drainage. On the 17 th day of the second cycle of chemotherapy, the patient succumbed to bacterial septicemia.

\section{Discussion}

Serous effusions are encountered in the course of lymphomas. Although the frequency of pleural effusion is $20-30 \%$ in non-Hodgkin's lymphoma (NHL) and Hodgkin's disease, the involvement of peritoneal and pericardial cavities is uncommon [6]. In a series of 101 cases of malignant ascites, Runyon and Hoefs [7] reported lymphomas as the underlying cause for $8 \%$ of cases. In another analysis of 100 patients with ascites by Mahmood et al. [8], lymphoma was accounted for $2 \%$ of cases. In the absence of obstructive or infiltrative tumor mass, the pathogenesis of serosal involvement in lymphomas has been attributed to vascular leakage caused by stimulation of vascular endothelial growth factor. Direct infiltration is the predominant cause of serosal involvement in NHL. The differential diagnosis of serous effusions in the course of lymphomas includes reactive lymphocytoses, small round-cell tumors and presence of cells simulating Reed-Sternberg cells [6]. Combined morphology and immunophenotyping of serous fluids by FCM has a sensitivity and specificity of $100 \%$. When peritoneal effusion is suspected as a manifestation of a lymphoproliferative disease, paracentesis is the initial choice of diagnostic and therapeutic procedure. In such cases, cytology along with FCM yields a quick diagnosis.

MCL, a mature B-cell NHL, often shows aggressive biologic behavior. Common sites of involvement are lymph nodes, spleen (45-60\%), Waldeyer's ring, bone marrow $(>60 \%)$, blood (13-77\%) and extranodal sites including the gastrointestinal tract $[9,10]$. Our patient had massive splenomegaly in the absence of marked enlarged lymphadenomegaly, not an uncommon finding in MCL. Yet, involvement of serous cavities is not a usual presentation. The dominant clinical problem encountered in our patient was massive ascites. MCL cells express pan-B cell antigens (e.g. CD19, CD20), CD5 and FMC7. Rare cases may be CD5- or CD23+ [11]. In our patient, CD23 expression was noted in peripheral blood and peritoneal fluid, but not in the bone marrow tissue. A retrospective study suggested that discordant antigen expression in samples from different body sites of the same patient is rare, yet possible [12].

Development of pleural effusion in the course of lymphomas, either primary or otherwise, is considered as one of the adverse factors affecting overall survival. Experience with peritoneal effusion resulting from direct infiltration with lymphoma is limited. The presence of serosal involvement in our patient, who had high IPI score at initial presentation (old age, elevated LDH level, stage IV, performance status 2), also may have contributed to the poor outcome. 
Bloody ascites with RBC $>50,000 / \mathrm{ml}$ develops in approximately $5 \%$ of patients with cirrhosis. In cirrhotic patients, bloody ascites most commonly develops following a traumatic paracentesis. Nontraumatic bloody ascites in the course of cirrhosis often suggests an underlying malignancy such as hepatocellular carcinoma [13]. Approximately $20 \%$ of the samples of patients with malignant ascites are bloody and in the majority of cases, hepatocellular carcinoma is the underlying cause [14]. On the other hand, only $10 \%$ of samples from patients with peritoneal carcinomatosis are bloody. Rare reports of lymphoma-associated bloody ascites have been previously published $[15,16]$. In two cases, the underlying hematologic disease was primary splenic lymphoma $[15,16]$ and MCL in another case [17]. Our patient presented with bloody ascites with a serum ascites albumin gradient (SAAG) $<1.1 \mathrm{~g} / \mathrm{dl}$. The most common causes of a low SAAG are peritoneal carcinomatosis $(10 \%)$ and tuberculosis (2\%) [18]. Patterns of mesenteric tumor spread in peritoneal lymphomatosis are indistinguishable from those seen in peritoneal carcinomatosis or tuberculous peritonitis [19]. The normal acid-fast staining and negative BACTEC culture of our patient's ascitic fluid render a diagnosis with tuberculous ascites unlikely. The concomitant presence of increased density in the form of streak infiltrations in the mesenteric area, minimally enlarged cervical and axillary lymph nodes and massive splenomegaly made us suspect peritoneal lymphomatosis as the underlying cause of massive ascites rather than peritoneal carcinomatosis. Our patient presented with a high total protein level ( $>2.5 \mathrm{~g} / \mathrm{dl})$, high LDH $(>480 \mathrm{U} / \mathrm{l}$, the upper limit of normal for serum), low glucose concentration $(<50 \mathrm{mg} / \mathrm{dl})$ and sterile ascites, all of which are compatible with the laboratory features of peritoneal lymphomatosis [7]. FCM of ascitic fluid and bone marrow investigations confirmed the diagnosis of MCL.

To our knowledge, only two cases of MCL presenting predominantly with ascites have been reported to date $[17,20]$. The common feature of the previous cases and our case was the contribution of the cytological work-up of ascites to a rapid diagnosis. Yet, FCM analysis as conducted in our patient was performed in only one previous case [20]. In one of the reported cases, intraperitoneal administration of rituximab resulted in a sustained local and systemic response [20]. Similar to our findings, the ascitic fluid was bloody in one case [17] while in the other previous case, ascitic fluid cell counts were not reported [20]. To the best of our knowledge, this is thus the second reported case of MCL presenting with bloody ascites.

Ascites as the initial clinical manifestation of MCL as in our case is rare. In our case, it can be speculated that the underlying pathophysiology of bloody ascites is related to involvement of the hepatic parenchyma or the peritoneal surface by malignant lymphocytes. In $<1 \%$ of cases, the underlying cause for ascites is associated with conditions other than liver and cardiac disease or solid tumors. In noncirrhotic patients presenting with massive splenomegaly and bloody ascites, physicians should be advised to consider the possible involvement of hematological diseases as well.

With increasing experience and awareness of peritoneal involvement in lymphoma, intraperitoneal chemotherapy may be a valuable treatment modality and should be considered if the benefit of therapy outweighs the risks of systemic chemotherapy [21]. 


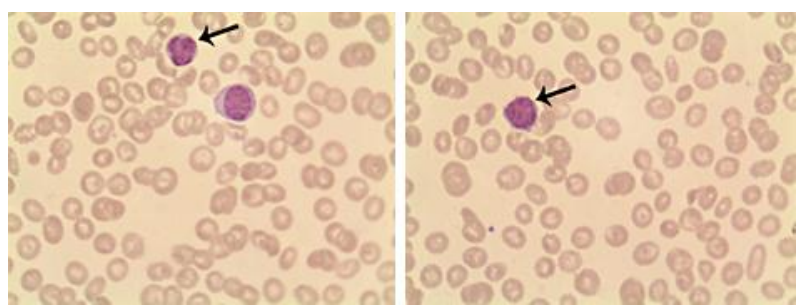

Fig. 1. Peripheral smear demonstrated small lymphocytes with irregular nuclei (left arrow) and rare cytoplasmic projections (right arrow).
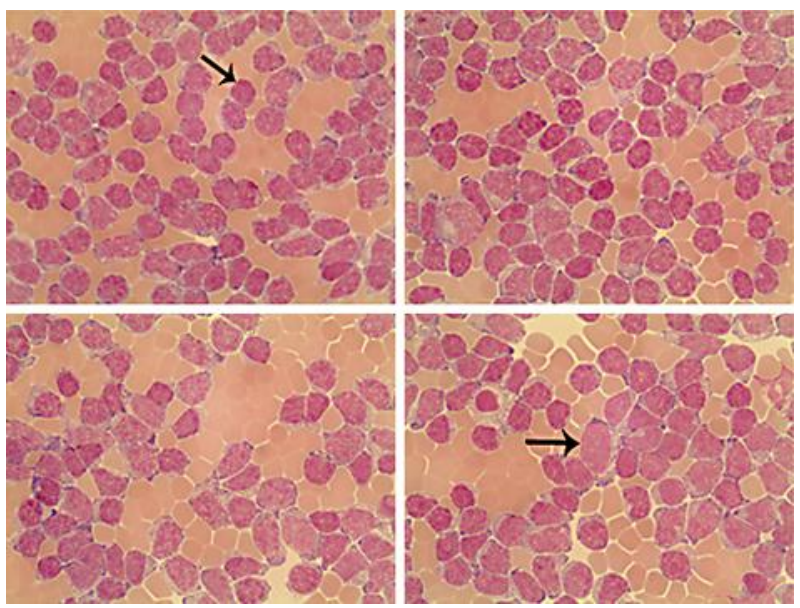

Fig. 2. Appearance of small (upper arrow) to medium-sized lymphocytes (lower arrow) with sparse cytoplasm and irregular nuclei with moderately dispersed chromatin in the ascitic fluid. 

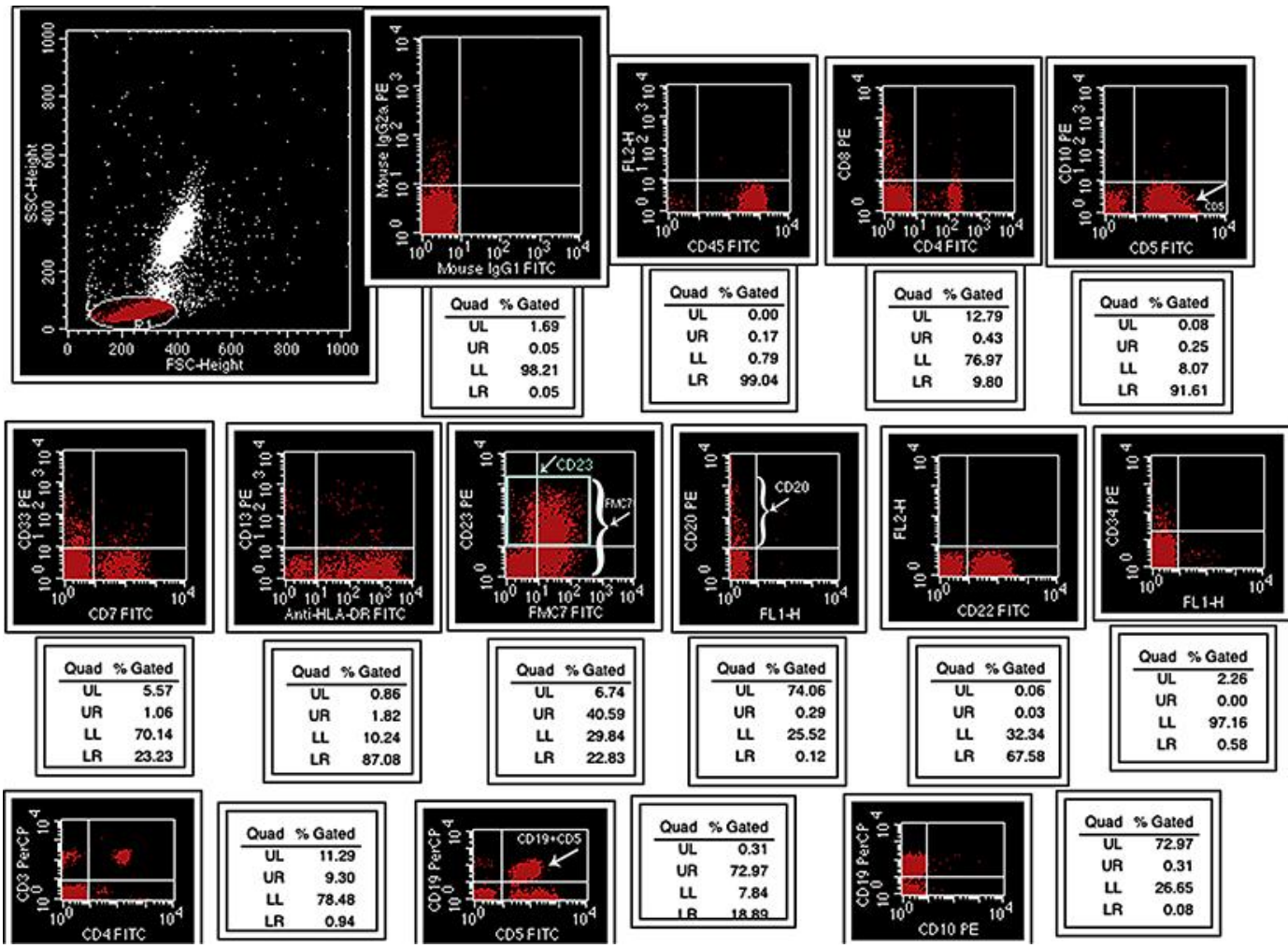

Fig. 3. On FCM immunophenotyping of the ascitic fluid, lymphoma cells showed CD5 (1st line 5th image), FMC7 and weak CD23 (2nd line 3rd image), CD20 (2nd line 4th image) and concomitant CD19 and CD5 (3rd line 2nd image) expression, compatible with a diagnosis of chronic lymphocytic leukemia/small lymphocytic lymphoma and MCL.

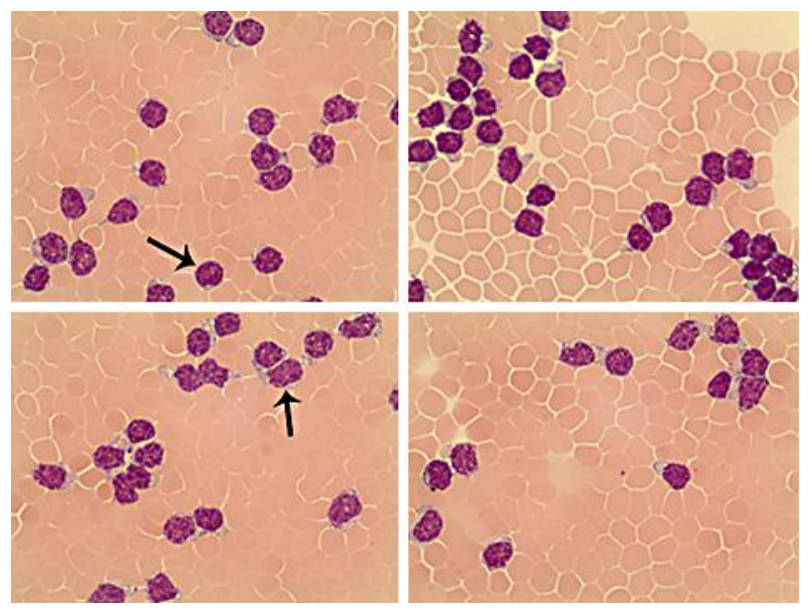

Fig. 4. Appearance of small lymphocytes (upper arrow) to medium-sized lymphocytes (lower arrow) with sparse cytoplasm and irregular nuclei with moderately dispersed chromatin in the pleural fluid. 


\section{References}

1 Attanoos R: Lymphoproliferative conditions of the serosa. Arch Pathol Lab Med 2012;136:268-276.

2 Lin YN, Chou JW, Chuang PH, Cheng KS, Peng CY, Chiang IP: Primary small intestinal natural killer/T cell lymphoma mimicking tuberculous peritonitis: report of a case and review of the literature. Intern Med 2011;50:515-518.

-3 Stancel GA, Coffey D, Alvarez K, Halks-Miller M, Lal A, Mody D, Koen T, Fairley T, Monzon FA: Identification of tissue of origin in body fluid specimens using a gene expression microarray assay. Cancer Cytopathol 2012;120:62-70.

-4 Karaosmanoglu D, Karcaaltincaba M, Oguz B, Akata D, Ozmen M, Akhan O: CT findings of lymphoma with peritoneal, omental and mesenteric involvement: peritoneal lymphomatosis. Eur J Radiol 2009;71: 313-317.

5 A predictive model for aggressive non-Hodgkin's lymphoma. The International Non-Hodgkin's Lymphoma Prognostic Factors Project. N Engl J Med 1993;329:987-994.

-6 Das DK: Serous effusions in malignant lymphomas: a review. Diagn Cytopathol 2006;34:335-347.

7 Runyon BA, Hoefs JC: Peritoneal lymphomatosis with ascites. A characterization. Arch Intern Med 1986;146:887-888.

8 Mahmood G, Debnath CR, Mandal AK: Evaluation of 100 cases of ascites. Mymensingh Med J 2009;18: 62-66.

-9 Romaguera JE, Medeiros LJ, Hagemeister FB, Fayad LE, Rodriguez MA, Pro B, Younes A, McLaughlin P, Goy A, Sarris AH, Dang NH, Samaniego F, Brown HM, Gagneja HK, Cabanillas F: Frequency of gastrointestinal involvement and its clinical significance in mantle cell lymphoma. Cancer 2003;97: 586-591; erratum in: Cancer 2003;97:3131.

10 Ferrer A, Salaverria I, Bosch F, Villamor N, Rozman M, Beà S, Giné E, López-Guillermo A, Campo E, Montserrat E: Leukemic involvement is a common feature in mantle cell lymphoma. Cancer 2007;109: 2473-2480.

11 Dorfman DM, Pinkus GS: Distinction between small lymphocytic and mantle cell lymphoma by immunoreactivity for CD23. Mod Pathol 1994;7:326-331.

12 Bangerter M, Hildebrand A, Griesshammer M: Immunophenotypic analysis of simultaneous specimens from different sites from the same patient with malignant lymphoma. Cytopathology 2001;12:168-176.

13 DeSitter L, Rector WG Jr: The significance of bloody ascites in patients with cirrhosis. Am J Gastroenterol 1984;79:136-138.

14 Runyon BA, Hoefs JC, Morgan TR: Ascitic fluid analysis in malignancy-related ascites. Hepatology 1988;8: 1104-1109.

15 Hacker JF 3rd, Richter JE, Pyatt RS, Fink MP: Hemorrhagic ascites: an unusual pres entation of primary splenic lymphoma. Gastroenterology 1982;83:470-473.

16 Healy NA, Conneely JB, Mahon S, O’Riardon C, McAnena OJ: Primary splenic lymphoma presenting with ascites. Rare Tumors 2011;3:e25.

17 Mohamed G, Kochlef A, Gargouri D, Kilani A, Elloumi H, Ouakaa A, Belhadj N, Romani M, Kharrat J, Ghorbel A: Monoclonal gammopathy and primary colonic mantle cell lymphoma. Rev Med Interne 2009;30:279-281.

18 Muñoz Codoceo C, Pérez Carreras M, Garrido Ruiz M, Martínez González MA, Ulloa Márquez E, Yela San Bernardino C, Solís Herruzo JA: Ascites and constitutional syndrome in a 70-year-old woman. Rev Esp Enferm Dig 2007;99:280-286.

19 Kim Y, Cho O, Song S, Lee H, Rhim H, Koh B: Peritoneal lymphomatosis: CT findings. Abdom Imaging 1998;23:87-90.

20 Crysandt M, Neumann B, Das M, Engelbertz V, Bendel M, Galm 0, Osieka R, Jost E: Intraperitoneal application of rituximab in refractory mantle cell lymphoma with massive ascites resulting in local and systemic response. Eur J Haematol 2007;79:546-549.

-21 Sangisetty SL, Miner TJ: Malignant ascites: a review of prognostic factors, pathophysiology and therapeutic measures. World J Gastrointest Surg 2012;4:87-95. 